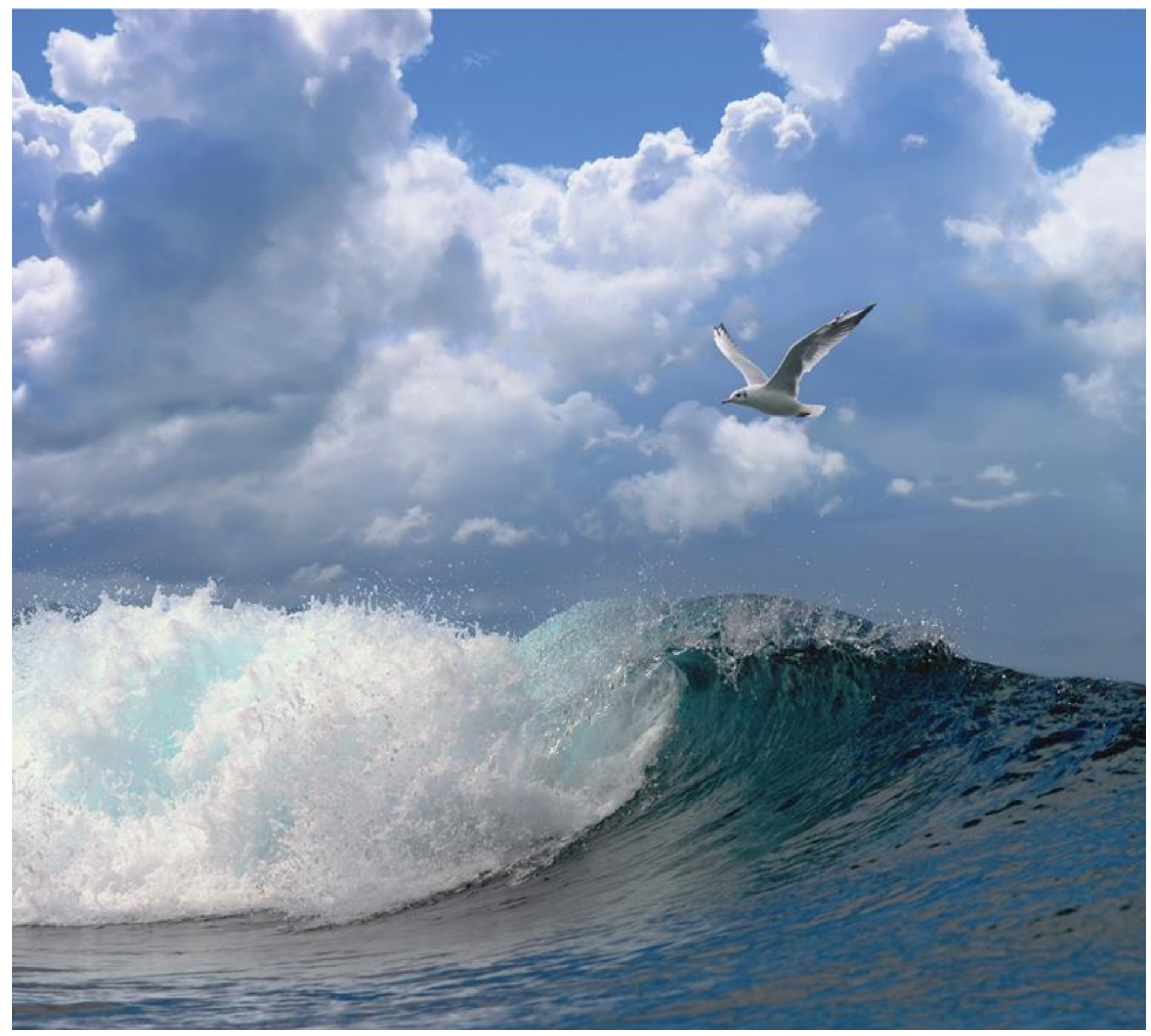

Bestandsopname van mosselen op mosselkweekpercelen in de Waddenzee in juni 2018 


\section{Bestandsopname van mosselen op mosselkweekpercelen in de Waddenzee in juni 2018}

Auteur(s): Jacob J. Capelle en Marnix R. van Stralen

Publicatiedatum: 6 september 2018 
Jacob J. Capelle, Marnix, R. van Stralen, 2018. Bestandsopname van mosselen op mosselkweekpercelen in de Waddenzee in juni 2018. Wageningen Marine Research Wageningen UR (University \& Research centre), Wageningen Marine Research rapport C063/18. 20 blz.

Keywords: mosselbestand, mosselkweek, Waddenzee

Opdrachtgever: Ministerie van LNV en PO Mosselcultuur

Dit rapport is gratis te downloaden van : https://doi.org/10.18174/459055

Wageningen Marine Research verstrekt geen gedrukte exemplaren van rapporten.

Wageningen Marine Research Wageningen UR is ISO 9001:2008 gecertificeerd.

(C) 2018 Wageningen Marine Research Wageningen UR

Wageningen Marine Research, onderdeel van Stichting Wageningen Research KvK nr. 09098104,

IMARES BTW nr. NL 8113.83.696.B16. Code BIC/SWIFT address: RABONL2U IBAN code: NL 73 RABO 0373599285
De Directie van Wageningen Marine Research is niet aansprakelijk voor gevolgschade, noch voor schade welke voortvloeit uit toepassingen van de resultaten van werkzaamheden of andere gegevens verkregen van Wageningen Marine Research opdrachtgever vrijwaart Wageningen Marine Research van aanspraken van derden in verband met deze toepassing.

Dit rapport is vervaardigd op verzoek van de opdrachtgever hierboven aangegeven en is zijn eigendom. Niets uit dit rapport mag weergegeven en/of gepubliceerd worden, gefotokopieerd of op enige andere manier gebruikt worden zonder schriftelijke toestemming van de opdrachtgever. 


\section{Inhoud}

Samenvatting

$1 \quad$ Inleiding

2 Werkwijze $\quad 6$

$2.1 \quad$ Bemonstering $\quad 6$

2.2 Berekeningen 6

$\begin{array}{llr}3 & \text { Resultaten } & 8\end{array}$

3.1 Mosselbestand $\quad 8$

3.2 Zeesterren en krabben $\quad 10$

$4 \quad$ Discussie en conclusie $\quad 13$

$\begin{array}{lr}\text { Literatuur } & 14\end{array}$

$\begin{array}{lr}\text { Verantwoording } & 15\end{array}$

$\begin{array}{lr}\text { Bijlage } 1 \text { werkvoorschrift monstername } & 16\end{array}$

Bijlage 2 Kaarten mosseldichtheid per grootteklasse $\quad 17$ 


\section{Samenvatting}

Een van de uitgangspunten bij de mosselzaadvisserij is dat de omvang van het mosselbestand in de Waddenzee en daarmee het voedselaanbod voor vogels niet minder is dan in een situatie dat niet wordt gekweekt en gevist. Dat betekent dat in het najaar een zekere hoeveelheid mosselen op de kweekpercelen in de Waddenzee aanwezig dient te zijn. Na de voorjaarsvisserij wordt met een bestandsopname een schatting gemaakt van het bestand op de kweekpercelen (de zogenaamde 'starthoeveelheid') en wordt vervolgens bijgehouden hoeveel mosselen afgevoerd worden en hoeveel mosselen erbij komen. Een tweede bestandsopname is bedoeld om te kunnen valideren of de eerder genoemde hoeveelheid mosselen aan het begin van de winter inderdaad op de percelen aanwezig is. In voorliggende rapportage wordt de bestandsopname op de percelen na de voorjaarszaadvisserij van 2018 gerapporteerd. Hiertoe zijn alle kweekpercelen in de Waddenzee waar mosselen verwacht worden in juni 2018 bemonsterd. Het totale bestand op de percelen eind juni is geschat op 71,0 miljoen $\mathbf{~ k g}$, netto en $\mathbf{1 0 3 , 0}$ miljoen $\mathbf{~ k g ~ b r u t o . ~ H e t ~ t o t a l e ~ b e s t a n d ~ i s ~ v o o r a l ~ d o o r ~ h e t ~ u i t b l i j v e n ~ v a n ~}$ een visbaar zaadbestand in 2017 minder groot dan in de laatste twee jaren (2016-2017) maar wel hoger dan in de periode daarvoor (2013-2015). Er zijn in juni 2018 relatief weinig zeesterren en krabben aangetroffen op de percelen. 


\section{$1 \quad$ Inleiding}

Eén van de uitgangspunten voor de mosselzaadvisserij is dat het geheel van vissen, kweek en afvoer van mosselen naar Zeeland ('VKA') niet leidt tot minder mosselen in de Waddenzee en daarmee tot minder voedsel voor overwinterende vogels dan in een situatie waarin niet zou worden gekweekt en gevist. De achtergronden hiervan zijn na te lezen in de passende beoordeling voor de mosselzaadvisserij (van Stralen, 2018) en de NB-wet vergunning die voor de periode 2018-2020 door het ministerie van Economische Zaken voor deze visserij is verleend (LNV, 2018).

Dit uitgangspunt betekent dat er in het najaar een zekere minimale hoeveelheid mosselen op de percelen aanwezig moet zijn. Voor het najaar van 2018 is dit minimale mosselbestand vastgesteld op 13.8 Miljoen $\mathrm{kg}$ (138.000 mt) netto versgewicht mosselen (Marinx-notitie,17 april 2018). Om dat te borgen wordt na de voorjaarsvisserij een schatting gemaakt van het bestand op de kweekpercelen (de zogenaamde 'starthoeveelheid') en wordt vervolgens bijgehouden hoeveel mosselen naar Zeeland worden afgevoerd en hoeveel mosselen erbij komen afkomstig uit MZI's, zaadvisserij in het najaar en andere bronnen (bijvoorbeeld 'Zuid-Noord' transporten, d.w.z. transporten van mosselen uit Zeeland naar de Waddenzee). Met een tweede bestandsopname in de winter, wordt gevalideerd of de vastgestelde minimale hoeveelheid mosselen aan het begin van de winter inderdaad op de percelen aanwezig is.

Het mosselbestand op de percelen na de voorjaarsvisserij (in week 18-21) van 2018 is geïnventariseerd in juni 2018. Resultaten van de inventarisatie worden hier gerapporteerd. Eventuele veranderingen in het bestand door groei en/of afvoer van mosselen in de periode tussen de voorjaarsvisserij in mei en de survey in juni zijn in dit rapport niet verwerkt. 


\section{Werkwijze}

\section{$2.1 \quad$ Bemonstering}

Alle kweekpercelen in de Waddenzee waar mosselen verwacht worden, zijn in juni 2018 bemonsterd. De bestandsopname is uitgevoerd zoals beschreven is in Van Stralen (2013). Hiervoor zijn bemonsteringsstations volgens een regelmatig grid over de kweekpercelen verdeeld. De bemonsteringsstations liggen in noordelijke en oostelijke richting 0,2 nautische minuten van elkaar, overeenkomend met een gridceloppervlakte van 8,26 ha. Kweekpercelen of gedeelten van kweekpercelen die in de winter niet voor mosselkweek gebruikt worden, zijn hierbij uitgesloten. Er is in de bemonstering gebruik gemaakt van hetzelfde grid als voor de bemonstering in de zomer van 2017 en in de winter van 2017/2018. Uitgangspunten voor de vaststelling van dit grid zijn beschreven in (Troost \& Van Stralen, 2017).

In totaal zijn 528 stations bemonsterd tussen 12 januari en 19 februari 2018 door buitendienst medewerkers van de Waddenunit van het Ministerie van EZ vanaf de Rijksvaartuigen "Asterias" en "Phoca". Per station zijn 5 happen genomen met een Van Veen bodemhapper wat resulteert in een bemonsterd oppervlak van $0,276 \mathrm{~m}^{2}$ per station.

De vijf happen genomen per monsterstation zijn samengevoegd tot één monster voor het uitzoeken van mosselen, zeesterren en krabben. Per monsterstation is het volume (in liters) van de mosselen bepaald. Zeesterren en (strand)krabben zijn incidenteel in de bodemhappen aangetroffen en zijn daarom per station uit de vangst gehaald en als dagtotaal gewogen. Per dag zijn de vangsten aan mosselen bijeengevoegd. Stations met vooral mosselzaad als vangst zijn daarbij apart gehouden van stations met voornamelijk halfwas (schelplengte kleiner dan $45 \mathrm{~mm}$ ) en/of al voor consumptiegeschikte mosselen (schelplengte van minstens $45 \mathrm{~mm}$ ). Dit levert per dag dus twee verzamelmonsters op: zaad en meerjarige mosselen (halfwas + consumptie). Aan het eind van de dag is van elk daarvan het volume bepaald (in liters) en zijn eventueel deelmonsters genomen voor zaad $(3,5 \mathrm{I})$ en meerjarige mosselen (6 I). Uit de (deel)monsters wordt het aandeel zaad, halfwas en consumptiegeschikte mosselen geselecteerd. De mosselen worden schoongemaakt, de hoeveelheid pokken wordt gewogen, zeesterren en krabben worden geteld en gewogen. Ten slotte worden de schoongemaakte mosselen geteld en gewogen. De handleiding voor de verwerking van deze monsters is bijgevoegd in Bijlage $\mathbf{1}$.

\subsection{Berekeningen}

Bij de zaadvisserij maar ook bij het verzaaien van bijvoorbeeld halfwasmosselen naar Zeeland wordt gerekend in bruto gewichten - dit zijn mosselen inclusies tarra, zoals wier, pokken, zeesterren en schelpresten. Er zijn daarom ook bruto bestandsschattingen gemaakt.

Bij de doorrekening van netto naar bruto hoeveelheden zaad en meerjarige mosselen is uitgegaan van tarrapercentages van respectievelijk $40 \%$ en $25 \%$. Dit is conform de berekeningen bij bestandsopnamen van wilde mosselbestanden.

De volgende berekeningen zijn uitgevoerd, per grootteklasse mosselen $(i)$ en per dag $(j)$ :

- $\quad$ De subsample factor: $f=\mathrm{V}_{\mathrm{d}} / \mathrm{V}_{\mathrm{d} \_\mathrm{s}} * \mathrm{~V}_{\mathrm{s} \_\mathrm{s}}$ met $V_{d}$ als Volume mosselen per dag $(I), V_{d_{\_} s}$ als Subsample uit $V_{d}(I)$ en $V_{s_{-} s}$ als Subsample uit $\mathrm{V}_{\mathrm{d} \_s}$ (aantal maal in gelijke delen).

- Totaal bemonsterde oppervlakte $\left(\mathrm{m}^{2}\right): O=s^{*} A$ (Tabel 2.1)

- Totale mosselbiomassa $(\mathrm{kg})$ verzameld voor de verschillende grootteklassen (i): $T_{i}=\Sigma f_{j} * W_{j}$ 
met $w$ als verzamelgewicht mosselen $(\mathrm{kg})$

- Mosselbiomassa per vierkante meter $\left(\mathrm{kg} / \mathrm{m}^{2}\right): B_{i}=T_{i} / O$

- $\quad$ Mosselbiomassa percelen (Miljoen kg): Bestand $=B_{i} * s^{*}$ grid/100 (Tabel 2.1)

- Totaal aantal mosselen verzameld: $N_{i}=\Sigma f_{j} * n_{j}$ met $n$ als aantal mosselen per station.

- Aantal mosselen per vierkante meter: $D_{i}=N_{i} / O$

- Individueel gewicht mosselen (g): $W_{i}=B_{i}^{*} 1000 / D_{i}$

Tabel 2.1 Parameters oppervlaktebepaling

\begin{tabular}{l|l|l|l}
\hline Parameter & Beschrijving & Eenheid & Waarde \\
\hline$S$ & Aantal bemonsterde stations & - & 528 \\
$A$ & Bemonsterde oppervlakte per station & $\mathrm{m}^{2}$ & 0,276 \\
grid & Oppervlakte per gridcel & ha & 8,26 \\
\hline
\end{tabular}




\section{Resultaten}

\subsection{Mosselbestand}

De aangetroffen dichtheden van mosselen zijn ruimtelijk weergegeven in Figuur 3.1. Een opsplitsing voor verschillende grootteklassen is bijgevoegd in Bijlage 2. De bijbehorende bestandsgroottes zijn, samen met de resultaten uit voorgaande jaren, samengevat in Tabel 3.1 en in Figuur 3.2.

Het mosselbestand op de percelen in de Waddenzee eind juni 2018 is geschat op 71,0 miljoen kg (710.000 mosselton, $1 \mathrm{mt}=100 \mathrm{~kg}$ ) netto versgewicht. Daarvan bestaat 25,0 miljoen $\mathrm{kg}$ uit mosselzaad (broedval 2017). Van de 46,0 miljoen $\mathrm{kg}$ meerjarige mosselen bestaat 22,3 miljoen kg uit halfwas mosselen (schelplengte kleiner dan $45 \mathrm{~mm}$ ) en 23,7 miljoen $\mathrm{kg}$ uit consumptiemosselen (schelplengte van minstens $45 \mathrm{~mm}$ ). Uitgaande van tarrapercentages van $40 \%$ en $25 \%$ voor respectievelijk mosselzaad en meerjarige mosselen komt de bruto mosselbiomassa op de percelen uit op 103,0 miljoen $\mathrm{kg}(1.030 .000 \mathrm{mt})$ versgewicht, waarvan 41,6 miljoen $\mathrm{kg}$ mosselzaad en 61,3 miljoen $\mathrm{kg}$ meerjarige mosselen.

Tabel 3.1. Het mosselbestand op mosselkweekpercelen in de Waddenzee vanaf 2004. Bij de omrekening van netto naar bruto hoeveelheden is voor mosselzaad en meerjarige mosselen uitgegaan van een tarrapercentage van resp. 45\% en $25 \%$. 1 Mosselton $(\mathrm{mt})=100 \mathrm{~kg}$. De gegevens tot en met 2011 zijn afkomstig uit (De Mesel \& Wijsman, 2011) en (Wijsman \& Jol, 2012).

\begin{tabular}{|c|c|c|c|c|c|c|c|c|}
\hline \multirow{2}{*}{$\begin{array}{l}\text { Mosselbestand } \\
\text { kweekpercelen } \\
\text { Waddenzee }\end{array}$} & \multicolumn{4}{|c|}{ Netto bestand (miljoen kg) } & \multicolumn{4}{|c|}{ Bruto bestand (mt x 1000) } \\
\hline & Zaad & $\begin{array}{l}\text { Halfwas } \\
(<45 \mathrm{~mm})\end{array}$ & $\begin{array}{c}\text { Groot } \\
(\geq 45 \mathrm{~mm})\end{array}$ & Totaal & Zaad & $\begin{array}{l}\text { Halfwas } \\
(<45 \mathrm{~mm})\end{array}$ & $\begin{array}{c}\text { Groot } \\
(\geq 45 \mathrm{~mm})\end{array}$ & Totaal \\
\hline $2004-$ dec & 1,0 & 15,2 & 31,9 & 48,1 & 17 & 203 & 425 & 644 \\
\hline 2005 & 8,9 & 0,9 & 5,2 & 14,9 & 148 & 12 & 69 & 228 \\
\hline 2006 & 1,0 & 5,8 & 29,0 & 35,8 & 17 & 77 & 387 & 481 \\
\hline 2007 & 17,5 & 2,5 & 15,3 & 35,3 & 291 & 33 & 204 & 528 \\
\hline 2008 & 11,8 & 2,1 & 15,8 & 29,7 & 196 & 28 & 211 & 435 \\
\hline 2009 & 15,4 & 2,8 & 28,3 & 46,5 & 257 & 38 & 377 & 672 \\
\hline 2010 & 7,6 & 11,0 & 28,9 & 47,5 & 127 & 147 & 385 & 659 \\
\hline 2011 - dec & 8,9 & 1,3 & 11,8 & 21,9 & 148 & 17 & 157 & 322 \\
\hline 2013 - jan & 39,6 & 1,5 & 5,6 & 46,7 & 660 & 20 & 74 & 754 \\
\hline 2013 - april & 52,5 & 1,7 & 4,7 & 58,9 & 875 & 23 & 62 & 960 \\
\hline $2013-$ dec & 14,3 & 31,1 & 4,7 & 50,1 & 238 & 415 & 63 & 716 \\
\hline 2014 - juli & 7,5 & 33,3 & 20,3 & 61,1 & 124 & 444 & 271 & 840 \\
\hline $2014-$ dec & 37,7 & 7,6 & 13,4 & 58,7 & 629 & 101 & 179 & 909 \\
\hline 2015 - juni & 40,7 & 11,7 & 13,5 & 65,8 & 678 & 155 & 180 & 1013 \\
\hline $2015-\mathrm{dec}$ & 45,6 & 9,5 & 12,4 & 67,5 & 761 & 126 & 165 & 1052 \\
\hline 2016 - juni & 62,6 & 21,3 & 15,2 & 99,1 & 1044 & 284 & 202 & 1530 \\
\hline $2017-$ feb & 48,1 & 14,6 & 9,1 & 71,8 & 802 & 195 & 121 & 1118 \\
\hline 2017 - juli & 80,3 & 20,4 & 18,0 & 118,8 & 1339 & 272 & 240 & 1851 \\
\hline $2018-$ feb & 20,8 & 20,2 & 9,3 & 50,4 & 346 & 270 & 125 & 741 \\
\hline 2018 - juni & 25,0 & 22,3 & 23,7 & 71,0 & 416 & 297 & 316 & 1030 \\
\hline gem. voorjaar '04-'17 & 44,8 & 18,4 & 15,9 & 79,1 & 746 & 246 & 212 & 1204 \\
\hline gem. winter '04-'17 & 19,8 & 8,1 & 16,2 & 44,2 & 330 & 109 & 217 & 655 \\
\hline
\end{tabular}




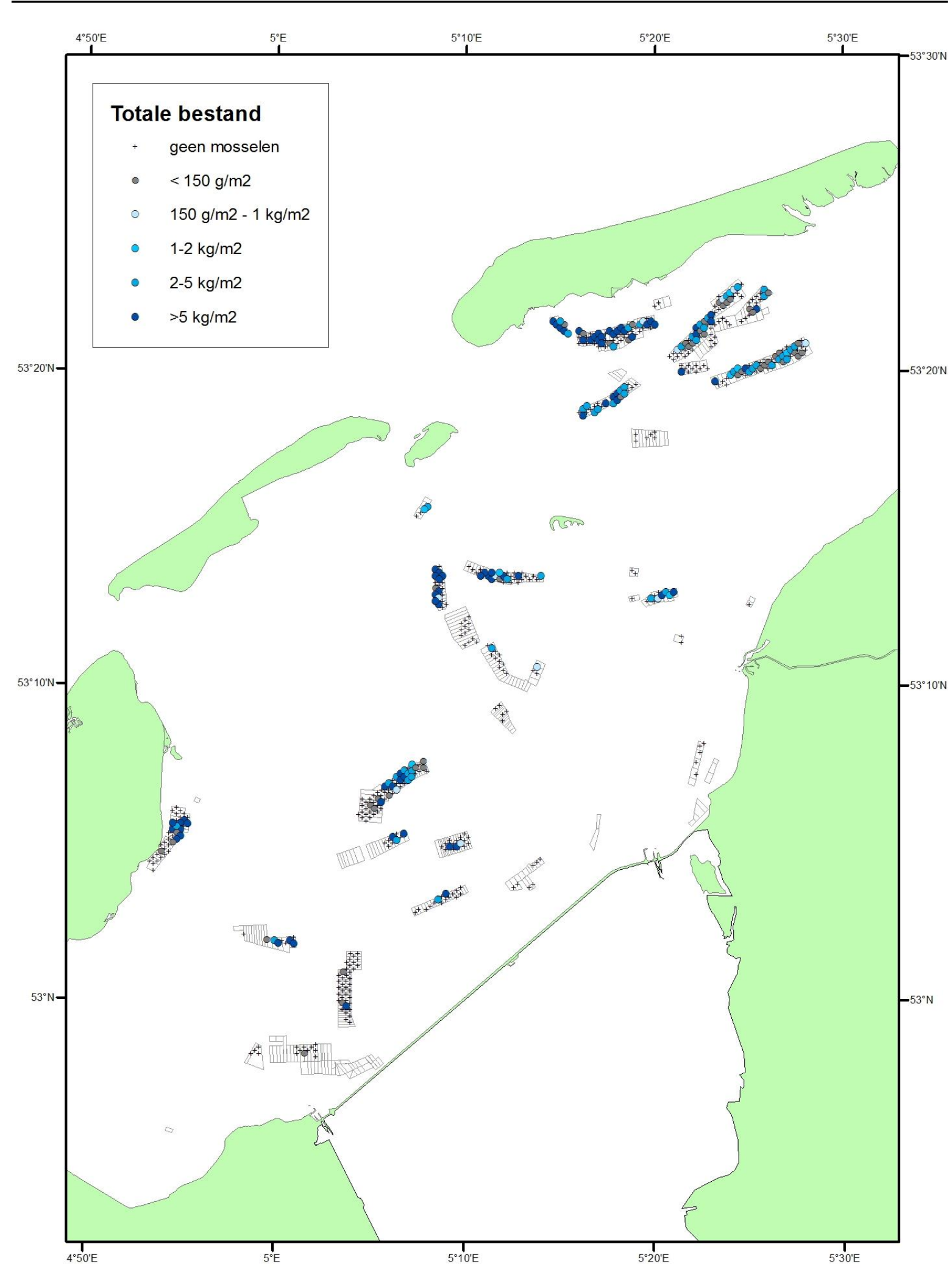

Figuur 3.1 Dichtheid van mosselen op mosselkweekpercelen in de Waddenzee in januari-februari 2018 in gram versgewicht per $\mathrm{m}^{2}$. 


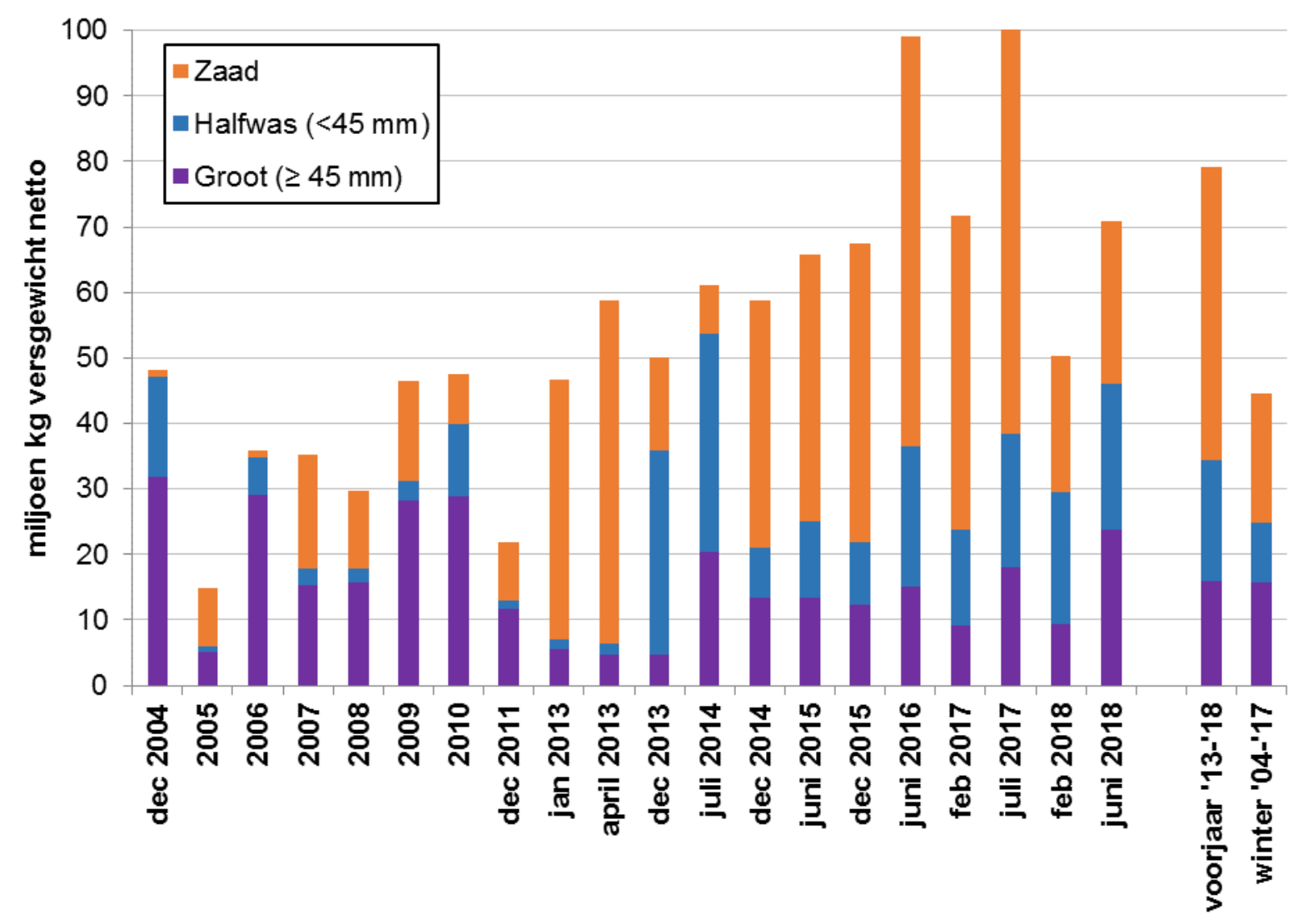

Figuur 3.2 Mosselbestand in miljoen $\mathrm{kg}$ netto versgewicht op mosselkweekpercelen in de Waddenzee in de periode december 2004 - juni 2018 met meest rechts de gemiddelde biomassa in het voorjaar van 2013-2018 en in de winters van 2004 - 2017. De mosselen zijn onderverdeeld in mosselzaad en meerjarige mosselen groter en kleiner dan $45 \mathrm{~mm}$. De onderliggende gegevens zijn opgenomen in Tabel 3.1.

\subsection{Zeesterren en krabben}

In Tabel 3.2 zijn de gemiddelde dichtheden en biomassa's van zeesterren (Asterias rubens) en krabben (Carcinus maenas) vanaf 2013 weergegeven. Het bestand van krabben en zeesterren en de dichtheid op de percelen (Figuur 3.4A/C) was in juni 2018 lager dan in voorgaande jaren. Het gemiddelde individuele gewicht van krabben is toegenomen, van zeesterren is dit afgenomen sinds de winter van 2017/2018 (Figuur 3.4B). 
Tabel 3.2. Ontwikkeling van het bestand aan zeesterren en krabben groter dan $2 \mathrm{~cm}$ op kweekpercelen in de Waddenzee in de periode januari 2013 - juli 2017. IW = individueel gewicht. In januari 2013 zijn alleen de zeesterren bemonsterd.

\begin{tabular}{|c|c|c|c|c|c|c|c|c|}
\hline \multirow{3}{*}{$\begin{array}{l}\text { Predatoren op } \\
\text { percelen } \\
\text { Waddenzee }\end{array}$} & \multicolumn{4}{|c|}{ Zeesterren } & \multicolumn{4}{|c|}{ Krabben } \\
\hline & \multicolumn{2}{|c|}{ dichtheid } & \multirow{2}{*}{$\begin{array}{l}I W \\
\mathrm{~g}\end{array}$} & \multirow{2}{*}{$\begin{array}{l}\text { bestand } \\
\text { milj.kg }\end{array}$} & \multicolumn{2}{|c|}{ dichtheid } & \multirow{2}{*}{$\begin{array}{l}I W \\
\mathrm{~g}\end{array}$} & \multirow{2}{*}{$\begin{array}{l}\text { bestand } \\
\text { milj.kg }\end{array}$} \\
\hline & $\mathrm{n} / \mathrm{m}^{2}$ & $\mathrm{~g} / \mathrm{m}^{2}$ & & & $\mathrm{n} / \mathrm{m}^{2}$ & $\mathrm{~g} / \mathrm{m}^{2}$ & & \\
\hline 2013 - jan & 0,158 & 3,73 & 23,6 & 0,134 & & & & \\
\hline $2013-a p r$ & 0,152 & 2,99 & 19,6 & 0,076 & 0,621 & 10,07 & 16,2 & 0,257 \\
\hline $2013-$ dec & 0,709 & 7,43 & 10,5 & 0,291 & 0,709 & 5,99 & 8,4 & 0,235 \\
\hline 2014 - juli & 0,448 & 9,93 & 22,2 & 0,345 & 0,904 & 11,93 & 13,2 & 0,415 \\
\hline $2014-$ dec & 0,178 & 6,62 & 37,2 & 0,245 & 1,116 & 16,79 & 15,0 & 0,621 \\
\hline 2015 - juni & 0,229 & 7,77 & 33,9 & 0,294 & 0,736 & 9,23 & 12,5 & 0,349 \\
\hline $2015-\mathrm{dec}$ & 0,725 & 20,63 & 28,5 & 0,784 & 0,922 & 13,01 & 14,1 & 0,494 \\
\hline 2016 - juni & 2,815 & 12,12 & 4,3 & 0,453 & 0,840 & 9,50 & 11,3 & 0,356 \\
\hline $2017-\mathrm{feb}$ & 0,605 & 10,48 & 17,3 & 0,430 & 1,159 & 8,66 & 7,5 & 0,356 \\
\hline 2017 - juli & 1,290 & 30,14 & 23,4 & 1,167 & 0,773 & 11,84 & 15,3 & 0,459 \\
\hline $2018-$ feb & 0,248 & 6,51 & 26,3 & 0,283 & 0,474 & 7,93 & 16,7 & 0,345 \\
\hline 2018 - jun & 0,229 & 2,21 & 9,65 & 0,095 & 0,264 & 5,18 & 19,62 & 0,224 \\
\hline gem winter '13-17' & 0,437 & 9,23 & 23,9 & 0,361 & 0,876 & 10,48 & 12,4 & 0,410 \\
\hline gem alle waarn. & 0,649 & 10,04 & 21,4 & 0,383 & 0,774 & 10,01 & 13,6 & 0,374 \\
\hline
\end{tabular}

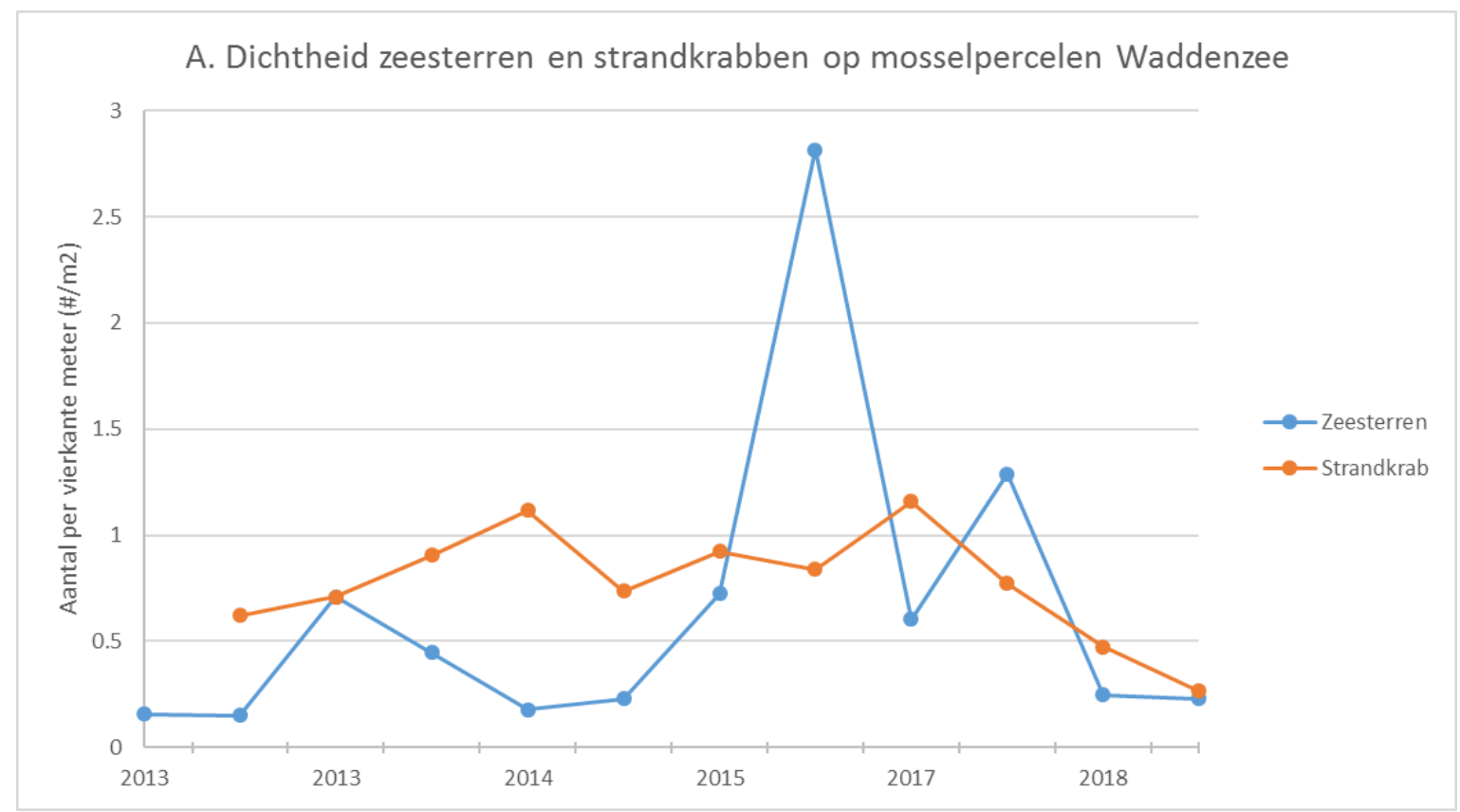




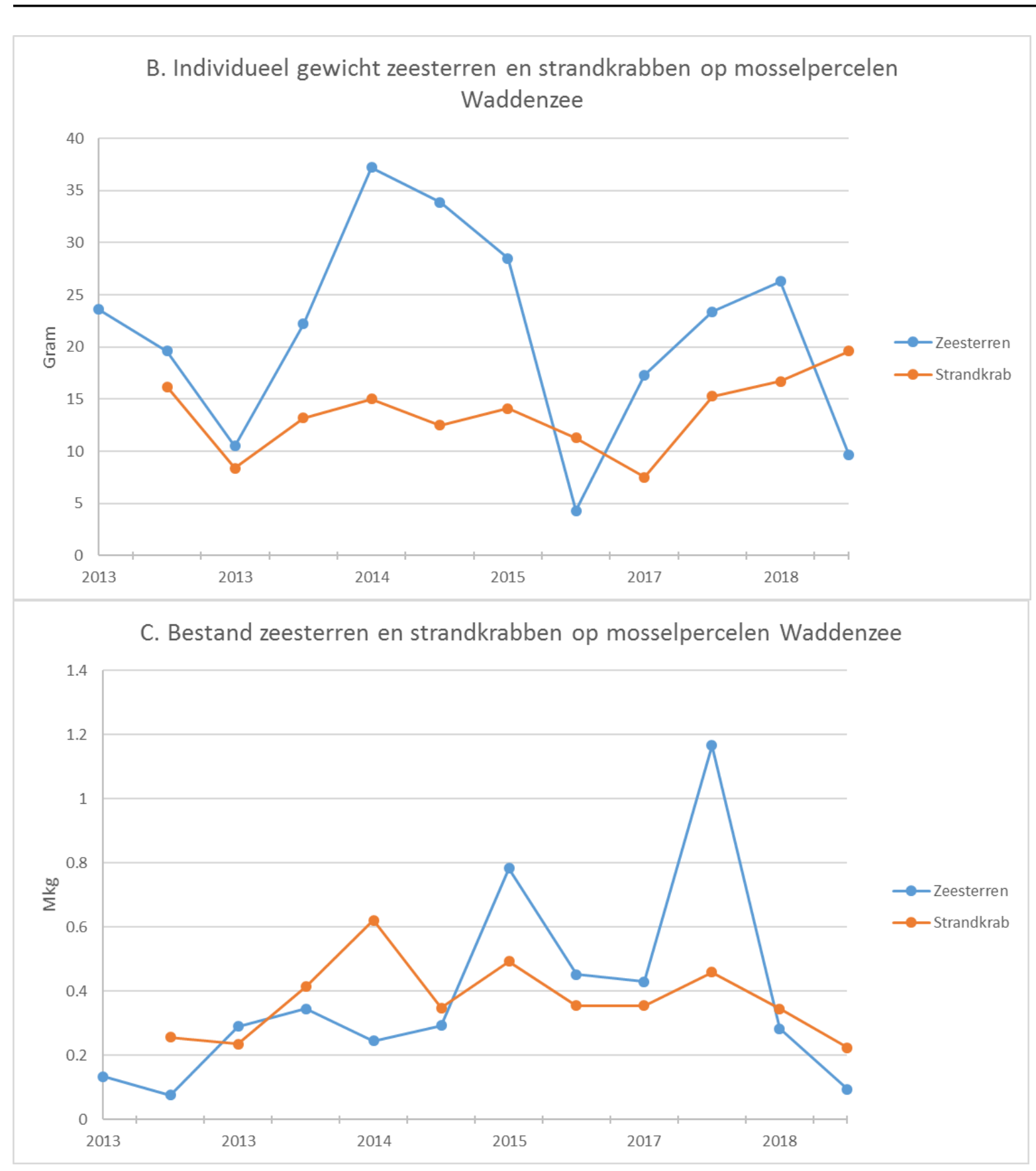

Figuur 3.4 Aanwezigheid van zeesterren en krabben (carapaxbreedte $>2 \mathrm{~cm}$ ) op mosselkweekpercelen in de Waddenzee in de periode 2013 - 2018. De onderliggende gegevens zijn opgenomen in Tabel 3.2; A: gemiddelde dichtheid in aantal per $\mathrm{m}^{2}$, B: gemiddeld gewicht per individuele zeester of krab in gram versgewicht, C: bestand aan zeesterren en krabben op de kweekpercelen in miljoen kg versgewicht. 


\section{$4 \quad$ Discussie en conclusie}

Het mosselbestand op de percelen in juni 2018 kenmerkt zich door een vergelijkbaar aandeel van de grootteklassen zaad (25 Mkg), halfwas (22 Mkg) en consumptie (24 Mkg). Het aandeel consumptiemosselen $(>4.5 \mathrm{~cm}$ ) is ten opzichte van voorgaande jaren relatief groot. In 2016 heeft voor het laatst een omvangrijke zaadval plaatsgevonden. De mosselen op de percelen afkomstig van de visserijen op de wilde bestanden (meest recente visserijen in najaar 2016, in voorjaar 2017 en in voorjaar 2018) zijn daarom inmiddels al bijna 2 jaar oud. Daarnaast viel in 2017 de groei op de percelen tegen, hierdoor zijn in 2017 minder mosselen van de percelen geleverd dan gewoonlijk, wat ook bijdraagt aan het relatief grote aandeel consumptiemosselen in deze perceelbemonstering. Het zaadbestand is afkomstig uit de MZI oogst in 2017. Bodemzaad uit 2017 was niet aanwezig en kon niet worden gevist. Het totale bestand is met $71 \mathrm{Mkg}$ netto en $103 \mathrm{Mkg}$ bruto, door het uitblijven van een visbaar zaadbestand in 2017 minder groot dan in de laatste twee jaren (2016-2017) maar wel hoger dan in de periode daarvoor (2013-2015).

Er zijn in juni 2018 relatief weinig zeesterren en krabben aangetroffen op de percelen. Uit voorgaande jaren blijkt dat het vooral het bestand aan zeesterren beïnvloed wordt door het mosselbestand (Capelle \& van Stralen, 2018). Het uitblijven van een zaadval in 2017 en lage dichtheden sterren in 2017 past in dit beeld. Het krabbenbestand was ook relatief laag, maar de krabben waren gemiddeld genomen wel groter dan in voorgaande bemonsteringen. 


\section{Literatuur}

Capelle JJ, van Stralen MR (2018) Bestandsopname van mosselen op mosselkweekpercelen in de Waddenzee in februari 2018. Wageningen Marine Research, Yerseke.

De Mesel I, Wijsman JWM (2011) Bestandsschatting mosselen op percelen in de Oosterschelde (1992-2009) en de Waddenzee (2004-2009). Yerseke.

LNV (2018) Nb-wet vergunning voor de mosselzaadvisserijen, 2018-2020. Kenmerk DGAN-NB/18 / 18034015 , ministerie van EZ, Den Haag.

Troost K, Van Stralen MR (2017) Bestandsopname van mosselen op mosselkweekpercelen in de Waddenzee in juli 2017, . Wageningen Marine Research Wageningen UR (University \& Research centre), Wageningen Marine Research, rapport C070/17.

van Stralen MR (2018) Passende Beoordeling van de mosselvisserij in het sublitoraal van de Westelijke Waddenzee in de periode 2018-2020. Marinx, Scharendijke.

Wijsman JWM, Jol J (2012) Onderzoeksproject Duurzame Schelpdiervisserij (PRODUS). Deelproject $1 \mathrm{~A}$. Bepaling bestand op de mosselpercelen in de Waddenzee najaar 2011 (Mussel stock assessment on culture plots in the Waddensea in autumn 2012, report in Dutch). Wageningen IMARES, Yerseke, pp. 48. 


\section{Verantwoording}

Rapport C063/18

Projectnummer: 4313200007-07 KOMPRO 1

Dit rapport is met grote zorgvuldigheid tot stand gekomen. De wetenschappelijke kwaliteit is intern getoetst door een collega-onderzoeker en het verantwoordelijk lid van het managementteam van Wageningen Marine Research

Akkoord:

Johan Craeymeersch

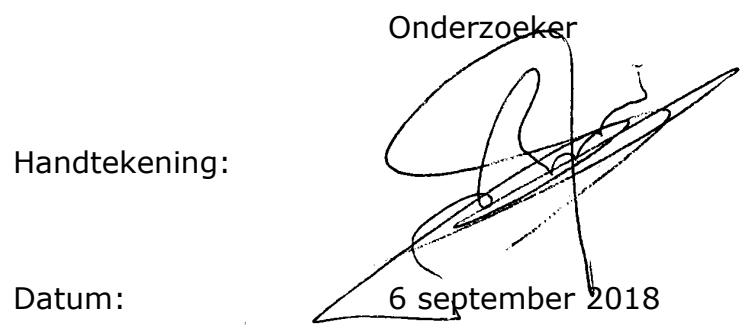

Akkoord:

Jakob Asjes

Manager Integratie

Handtekening:

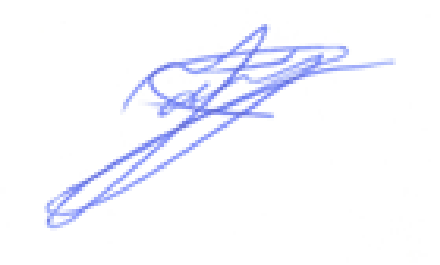

Datum:

6 september 2018 


\section{Bijlage 1 werkvoorschrift monstername}

\section{Handleiding bemonstering mosselpercelen}

versie 7 november 2014

\section{Monstername per station}

- Op elk station $\mathbf{5}$ happen

- Bij elkaar in een mand, spoelen

- Zeesterren uit de vangst halen, aantal noteren en bewaren in verzamel-emmer

- Idem voor krabben met schild groter dan $2 \mathrm{~cm}$ (duimnagel)

- Volume van de vangst bepalen in bekerglas. Aflezen in tienden liters. Wanneer het maar een paar mosselen zijn ("bewijsje") een "B" invullen. Wanneer er geen mosselen in de vangst zitten kan tarra over boord en is de vangst "nul".

- Bewaren in verzamelmand Zaad c.q. Halfwas + Cons. Bij mengsel indelen op dominante soort

- Aan dek: sample nummers ("treknummers" van die dag) invullen

- Brug: trek nummers noteren op de kaartjes.

Invullen meetlijst aan dek

De blauwe waarden moeten worden ingevuld, hier als voorbeeld

\begin{tabular}{|c|c|c|c|c|c|c|c|c|c|c|c|}
\hline 1 & 2 & 3 & 4 & 5 & 6 & 1 & 2 & 3 & 4 & 5 & 6 \\
\hline \multicolumn{8}{|c|}{ Bestandsopname percelen - bodemhapper } & \multicolumn{4}{|c|}{${ }^{*} \mathrm{Bij}$ heel weinig vangstvolume = "B" } \\
\hline \multicolumn{4}{|c|}{ Datum: 14 juni 2014} & Gebied: & \multicolumn{4}{|c|}{ Oosterom en Noorderbalgen } & $r$ & blad: & 1 \\
\hline $\begin{array}{c}\text { Sample } \\
\mathrm{nr} .\end{array}$ & $\begin{array}{c}\text { Station } \\
\mathrm{nr} .\end{array}$ & $\begin{array}{c}\text { Zeester } \\
\text { aantal } \\
\end{array}$ & $\begin{array}{l}\text { Krab } \\
\text { aantal }\end{array}$ & $\begin{array}{c}\text { Mossel } \\
z-m j\end{array}$ & $\begin{array}{c}\text { Volume } \\
\text { liter* }\end{array}$ & $\begin{array}{c}\text { Sample } \\
n r .\end{array}$ & $\begin{array}{c}\text { Station } \\
\mathrm{nr} .\end{array}$ & $\begin{array}{c}\text { Zeester } \\
\text { aantal } \\
\end{array}$ & $\begin{array}{l}\text { Krab } \\
\text { aantal }\end{array}$ & $\begin{array}{c}\text { Mossel } \\
z-m j\end{array}$ & $\begin{array}{c}\text { Volume } \\
\text { liter* }^{\star}\end{array}$ \\
\hline 1 & 123 & & & z & 2.3 & 41 & 325 & & & & \\
\hline 2 & 122 & & & z & B & 42 & & & & & \\
\hline 3 & 125 & & 2 & & & \multicolumn{2}{|c|}{ Met in kolom } & & & & \\
\hline 4 & 124 & 3 & & & & \multirow{7}{*}{\multicolumn{6}{|c|}{$\begin{array}{l}\text { 1. Het volgnummer (treknummer). In de brug dit } \\
\text { nummers op de kaartjes noteren. } \\
\text { 2. Het stationsnummer. Zie de kaartjes / in } \\
\text { MaxSea. Aan het eind van de dag toevoegen. } \\
\text { 3. Het aantal zeesterren in de } 5 \text { happen. De } \\
\text { sterren bewaren in verzamel-emmer. } \\
\text { 4. Idem voor het aantal krabben met schild groter } \\
\text { dan } 2 \mathrm{~cm} \text { (duimnagel). } \\
\text { 5. Categorie mosselen: } Z \text { = (vooral) zaad; } \\
\text { Mj = (vooral) meerjarig (halfwas + groot). } \\
\text { 6. Volume van de vangst, aflezen met het } \\
\text { bekerglas. Wanneer het maar een paar } \\
\text { mosselen zijn ("bewijsje", < } 0.1 \text { liter) een "B" } \\
\text { invullen. Wanneer er geen mosselen in de } \\
\text { vangst zitten kan de tarra weg, de vangst is dan } \\
\text { "nul". }\end{array}$}} \\
\hline 5 & 118 & & & mj & 4.1 & & & & & & \\
\hline 6 & 110 & & & z & 0.2 & & & & & & \\
\hline 7 & 111 & & & & & & & & & & \\
\hline 8 & & & & & & & & & & & \\
\hline 9 & & & & & & & & & & & \\
\hline & & & & & & & & & & & \\
\hline
\end{tabular}


Uit de verzamelmanden wordt per dag een monster genomen en uitgezocht:

\section{Bepalen vangstvolume en het nemen van een subsample}

Van beide verzamelmanden vangstvolume bepalen in liters: grote zwarte emmer $=20$ liter, kleine zwarte emmer $=12$ liter of met maatbeker.

Volumes emmers graag nog even checken: Door de emmers met bekerglas te vullen met water.

- Vangst mengen en neem subsample op volume:

$>$ Zaad 3.5 liter $=1$ doorzichtig emmertje, uit "zaad" verzamel-mand

Meerjarig 6 liter $=$ wit emmertje, uit de andere mand

- Wanneer de vangst kleiner is dan 3.5 resp. 6 liter, dan de hele vangst als monster nemen.

\section{Uitzoeken subsamples}

Zie ook het voorbeeld zoals ingevulde tabel op volgende pagina

- Beide monsters liefst helemaal uitzoeken

- Uitzoeken op zaad, halfwas (= meerjarig en $<45 \mathrm{~mm}$ ) en groot (= meerj. en $>45 \mathrm{~mm}$ )

- Ontpokken

- Mosselen tellen en wegen, de kapotte mosselen alleen tellen

- Pokken wegen

- Zeesterren en krabben: tellen en wegen

- Bij later wegen de mosselen, krabben en zeesterren bewaren in water in verband met vochtverlies. 


\section{Bijlage 2 Kaarten mosseldichtheid per grootteklasse}

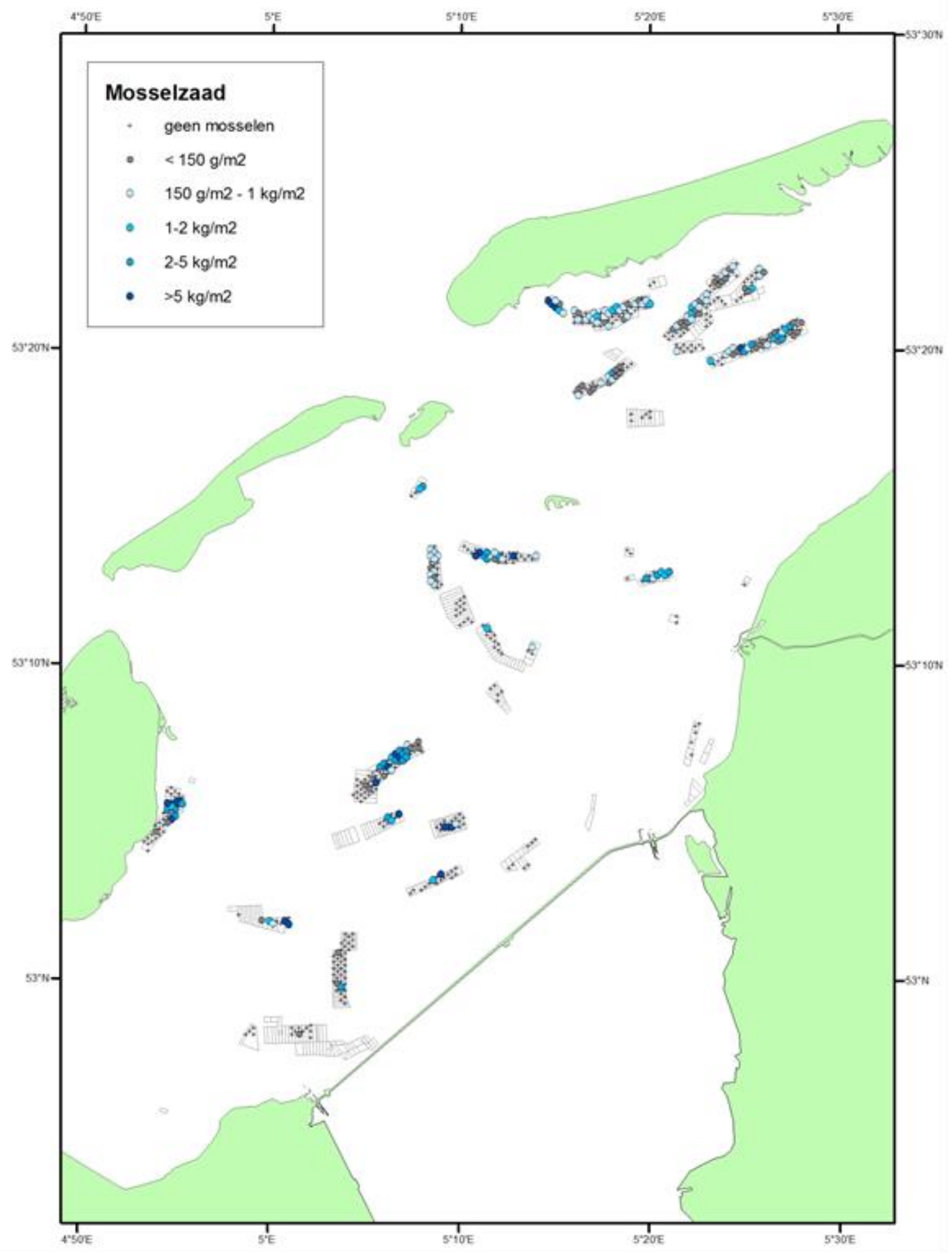




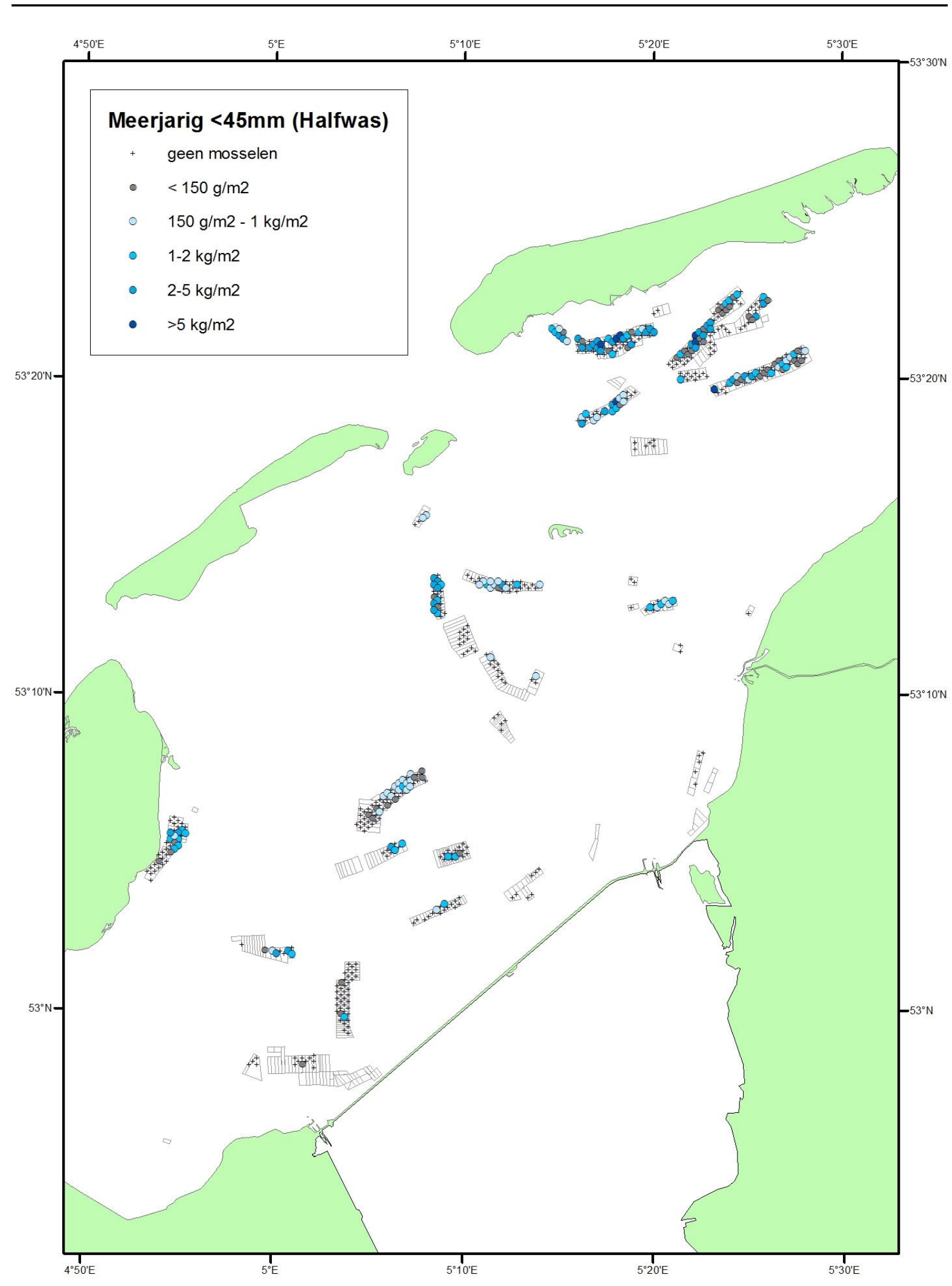




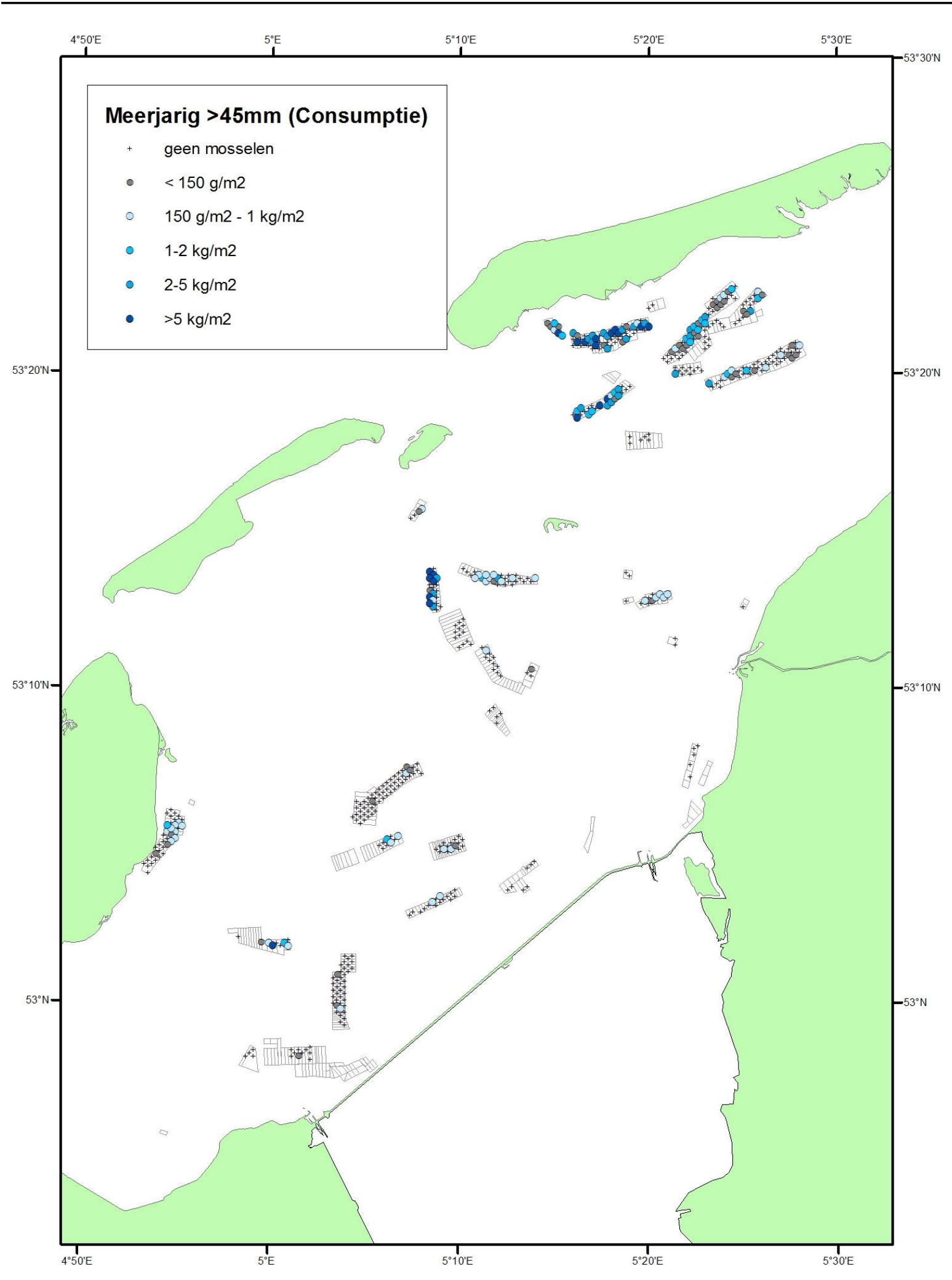

